\title{
Perception and Practice of Undergoing Glaucoma Screening among Ophthalmologists
}

\author{
Chimdia E. Ogbonnaya1, Lawrence U. Ogbonnaya², \\ Obiekwe Okoye ${ }^{3 *}$, Nkiru Akariwe ${ }^{4}$ \\ ${ }^{1}$ Department of Ophthalmology, Federal Teaching Hospital, Abakiliki, Nigeria \\ ${ }^{2}$ Department of Community Medicine, Federal Teaching Hospital, Abakiliki, Nigeria \\ ${ }^{3}$ Department of Ophthalmology, University of Nigeria, Enugu, Nigeria \\ ${ }^{4}$ Department of Ophthalmology, Enugu State University of Technology Teaching Hospital, Enugu, Nigeria \\ Email: *obiekwe.okoye@unn.edu.ng
}

Received 2 February 2016; accepted 1 May 2016; published 4 May 2016

Copyright (C) 2016 by authors and Scientific Research Publishing Inc.

This work is licensed under the Creative Commons Attribution International License (CC BY).

http://creativecommons.org/licenses/by/4.0/

c) (i) Open Access

\section{Abstract}

Background: Globally, glaucoma remains the leading cause of irreversible blindness. Early detection and treatment is mainstay of prevention of blindness from glaucoma. Purpose: This study was done to assess the perception and glaucoma screening practice of ophthalmologist in Nigeria. $\mathrm{Me}$ thods: This is a cross-sectional descriptive study. A pretested structured questionnaire was administered to all the ophthalmologists who attended the general plenary session of the 2013 annual conference of the Ophthalmological Society of Nigeria (OSN). Result: Of the 115 respondents, 63 $(54.8 \%)$ were females; mean age was $39.7 \pm 9.3$ years. Majority $69(60.0 \%)$ were less than 40 years old. Presence of systemic risk factors to glaucoma was reported by 19 (16.5\%), out of which $9(47.4 \%)$ were hypertension, $2(10.5 \%)$ were Diabetes Mellitus, $2(10.5 \%)$ were other cardiovascular diseases, and 6 were unspecified others. Among the respondents, 28 (24.3\%) had positive family history; $29(25.2 \%)$ had Myopia; and 3 (2.6\%) were known glaucoma patients already on treatment. Majority $91(79.1 \%)$ had positive attitude towards glaucoma screening. Although 98 $(85.2 \%)$ have ever had a full eye examination, only $56(48.7 \%)$ were routine. There was no statistically significant relationship between sex, age group, religion, positive family history, professional status, attitude and glaucoma screening. Conclusion: The attitude of Nigerian Ophthalmologists to glaucoma screening was high but actual screening practice was below expectation in view of their presumed high knowledge of the risk of blindness from glaucoma. In-house campaign aimed at promoting self-glaucoma screening among this high-cadre eye care providers is warranted.

\footnotetext{
${ }^{*}$ Corresponding author.
}

How to cite this paper: Ogbonnaya, C.E., Ogbonnaya, L.U., Okoye, O. and Akariwe, N. (2016) Perception and Practice of Undergoing Glaucoma Screening among Ophthalmologists. Open Journal of Ophthalmology, 6, 63-69. 
Keywords

\section{Glaucoma Screening, Perception, Practice, Ophthalmologists, Nigeria}

\section{Introduction}

Glaucoma is a blinding eye disease that affects the optic nerve. Broadly divided into open angle glaucoma (OAG) and closed angle glaucoma (CAG), it is the commonest cause of irreversible blindness and second only to cataract as the leading cause of blindness [1]. Though found all over the world, it is most common in Africans of West African origin [1].

Glaucoma prevalence has been increasing globally. Quigley and associate estimated that there were 60.5 million people with open angle glaucoma (OAG) and angle-closure glaucoma (ACG) in 2010, and predicted that this will increase to 79.6 million (out of which 58.91 million or $74 \%$ will be OAG) by the year 2020 [2]. It is further predicted that estimated 7.5 million persons would be blind from glaucoma [2]. The recent Nigeria National Blindness Survey amongst population aged 40 years and above shows that glaucoma is responsible for $16 \%$ of blindness, making it the second commonest cause of blindness in that age group [3].

Most patients are unaware of their eye condition and often present late. This is because the commonest form, open angle glaucoma, is symptomless at the earlier stage [4]. This late presentation of patients is higher in Africa [4] [5] with $29 \%$ - 53\% presenting blind and $48.5 \%$ - 70\% presenting at an advanced stage at first hospital visit.

Early detection of the disease through screening and prompt treatment helps to preserve the vision [6]-[8]. Some governments are already funding glaucoma screening services in order to improve detection in the presymptomatic stage [8] [9].

Awareness and knowledge of the disease are believed to influence treatment-seeking behavior of patients [10] [11]. Most studies done among glaucoma patients reveal poor level of glaucoma awareness before diagnosis [5] [7]. Ophthalmologists and those who work in the eye clinic have the highest level of awareness and knowledge about glaucoma [6]. However there needs to be correlation between glaucoma knowledge, positive perception and glaucoma screening practices of this eye care providers. To the best of the knowledge of the authors, there is no study that has been conducted in Nigeria regarding the glaucoma of screening behavior of ophthalmologists.

This study assessed the perception and glaucoma screening practice of ophthalmologists in Nigeria. While the findings will add to the data on the global glaucoma screening behavior and practices, it will further provide an evidence-based insight on the need for glaucoma screening promotion campaigns targeting this professional group.

\section{Materials and Methods}

Ophthalmological Society of Nigeria (OSN) is the umbrella professional body made up of Nigerian ophthalmology fellows/diplomates as members and ophthalmologists-in-training (residents) as associate members. A statutory member of International Council of Ophthalmology and Middle East African Council of Ophthalmology (MEACO), OSN provides a national platform for advocacy and training geared towards promotive and preventive eye care service provision in Nigeria.

Study design: This is a cross-sectional descriptive study.

All Nigerian ophthalmologists who attended the general plenary session of the annual congress of the Ophthalmological Society of Nigeria held from $27^{\text {th }}$ to $30^{\text {th }}$ August 2013 at Asaba, Delta State south-south Nigeria and who consented to participate in the survey were recruited in the study.

The study instrument developed originally was a structured questionnaire which sought information on respondents' socio-demographic characteristics, medical history, present ocular history, family ocular history, perception towards, and actual practice concerning glaucoma screening. To ascertain its construct validity, psychometric reliability, and ability to achieve the study objectives, the questionnaire was pretested on some ophthalmologists in Enugu south-east Nigeria. For the purpose of this study, glaucoma screening is defined as pre-symptomatic routine full eye examination by an ophthalmologist, repeated at intervals between 2 and 5 years. Ophthalmologists encompass fellows, ophthalmologists-in-training and diplomate ophthalmologists. 
Perception towards glaucoma screening was measured by asking respondents about respondent's need for glaucoma screening and how frequently an ophthalmologist should be seen for the purpose of getting screened for glaucoma.

Glaucoma screening practice was measured by asking respondents how many times and at what intervals respondents have gone for routine full eye examination. Optical status was assessed by enquiring about respondent's use of spectacles and type of refractive error.

This study presumed all respondents to be knowledgeable about glaucoma being ophthalmologists and so did not assess knowledge.

Data were entered into and analysed using the Statistical Package for Social Sciences (SPSS), version 18 (SPSS Inc., Chicago, Illinois, USA), and reported as frequency distributions, percentages and means \pm standard deviation. During data analyses, neutral responses like undecided or not sure were taken as a negative answer. Statistical tests for significance of observed inter-group differences were performed using the chi-squared or Fisher exact test for categorical variables. In all comparisons, odds ratios (OR) and 95\% confidence intervals (CI) associated with $\mathrm{p}<0.05$ were considered statistically significant.

Ethics: Ethics approval consistent with the tenets of 1964 Helsinki Declaration on research involving human subjects was obtained from Federal Teaching Hospital Abakiliki's Medical and Health Research Ethics Committee (Institutional Review Board).

Verbal informed consent was obtained from respondents before filling the questionnaire. To ensure confidentiality, all personal identifiers were removed during data collection, analysis and result presentation.

\section{Results}

The survey was conducted on a total of 115 ophthalmlogists comprising of 52 (45.2\%) males and 63 (54.8\%) females who were aged $39.7 \pm 9.3$ years (range, 27 - 65 years). Majority 69 (60.0\%) were less than 40 years old; Christians 101 (87.8\%); and residents 57 (49.6\%). Hypertension 19 (16.5\%) accounted for majority of systemic risk factors. A total of 28 (24.3\%) respondents have positive family history of glaucoma while 29 (25.2\%) had Myopia. Three (2.6\%) respondents were known glaucoma patients on medical treatment with 2 of the cases diagnosed during a routine glaucoma screening, Table 1.

The respondents' optical status is as shown in Table 2 with myopia accounting for majority 29 (25.2\%) of refractive error among study participants.

Respondents' perception towards glaucoma screening is as shown in Table 3 with majority 91 (79.1\%) showing a positive attitude towards glaucoma screening. Seventeen (14.8\%) respondents have never been screened for glaucoma.

There is no correlation between positive perception and gender $(p=0.7)$, age group $(p=0.08)$, religion $(p=$ $0.69)$, professional status $(p=0.21)$, positive family history $(p=0.55)$ and presence of myopia $(p=1.00)$. Good glaucoma screening practice was not associated with perception $(p=0.66)$, systemic risk factors $(p=0.36)$, presence of myopia $(p=0.84)$, positive family history $(p=0.57)$, gender $(p=0.97)$, age group $(p=0.21)$ and religion $(\mathrm{p}=0.36)$.

\section{Discussion}

To the best of our knowledge, no previous study has assessed the perception and glaucoma screening practice of ophthalmologists in Nigeria. In this survey general perception towards glaucoma screening was found to be high. This is probably due to an expected sound knowledge about the disease. Adegbehingbe et al. [6] reported that those who work in the ophthalmic unit as well as those who had relatives who had been blind from glaucoma had the highest knowledge about glaucoma, and considered it a priority eye disease.

This study observes that $48.7 \%$ of participants had regular and routine eye examination and glaucoma screening. A small but modest $14.8 \%$ have never received an eye examination or glaucoma screening tests. This suggests that knowledge do not necessarily translate to positive behavioral/screening practice. This is critical in the backdrop of the observed 2.6\% of known glaucoma patients among the participants of which $66.7 \%$ was diagnosed during a routine eye examination and glaucoma screening.

Routine eye examination especially targeting individuals with identifiable risk factors for the purpose of pre-symptomatic or early detection of glaucoma and appropriate treatment are the recommended practice for prevention of blindness from glaucoma [8] [9]. This is because the loss of vision often occurs gradually over a 
long period of time, and symptoms only occur when the disease is quite advanced. In spite of the challenge of weighting the cost-effectiveness of screening for POAG against its specificity and sensitivity; subjecting patients to an ophthalmologic investigation on the basis of the identified risk factors remains a fundamental preventive measure [12].

A study report that women are more likely to participate in regular eye health care and preventive health care in general compared to men [7]. However this study did not reveal any gender influence on glaucoma screening practice. There was also no statistical significance between uptake of eye examination and positive family history, religion or age.

Perhaps the high and relatively equal professional knowledge of the disease in this population may explain this trend.

The influence of age did not show statistical significance, however, the odds ratio was in favor of younger age

Table 1. Socio-demographic and medical characteristics of respondents.

\begin{tabular}{|c|c|c|}
\hline Characteristics & Frequency & Percentage \\
\hline \multicolumn{3}{|l|}{ Sex } \\
\hline Male & 52 & 45.2 \\
\hline Female & 63 & 54.8 \\
\hline \multicolumn{3}{|l|}{ Age group } \\
\hline$<40$ years & 69 & 60.0 \\
\hline$\geq 40$ years & 44 & 38.3 \\
\hline No response & 2 & 1.7 \\
\hline \multicolumn{3}{|l|}{ Religion } \\
\hline Christianity & 101 & 87.8 \\
\hline Islam & 11 & 9.6 \\
\hline Others & 3 & 2.6 \\
\hline \multicolumn{3}{|l|}{ Professional status } \\
\hline Consultant & 56 & 48.7 \\
\hline Resident & 57 & 49.6 \\
\hline No response & 2 & 1.7 \\
\hline \multicolumn{3}{|c|}{ Presence of systemic risk factor } \\
\hline Yes & 19 & 16.5 \\
\hline No & 90 & 78.3 \\
\hline No response & 6 & 5.2 \\
\hline \multicolumn{3}{|c|}{ Type of systemic risk factor $(n=19)$} \\
\hline Hypertension & 9 & 47.4 \\
\hline Diabetes mellitus & 2 & 10.5 \\
\hline Heart disease & 2 & 10.5 \\
\hline Others & 6 & 31.6 \\
\hline \multicolumn{3}{|c|}{ Presence of positive family history } \\
\hline Yes & 28 & 24.3 \\
\hline No & 78 & 67.8 \\
\hline No response & 9 & 7.9 \\
\hline
\end{tabular}

Table 2. Optical status of respondents.

\begin{tabular}{ccc}
\hline & F & $\%$ \\
\hline Do you use glasses & & \\
Yes & 69 & 60.0 \\
No & 44 & 38.3 \\
No response & 2 & 1.7 \\
Optical diagnosis & & \\
Refractive error & 48 & 41.7 \\
Presbyopia & 21 & 18.3 \\
Type of refractive error & & \\
Myopia & 29 & 25.2 \\
Hyperopia & 13 & 11.3 \\
Astigmatism & 6 & 5.2 \\
\hline
\end{tabular}


Table 3. Attitude and practice of glaucoma screening.

\begin{tabular}{|c|c|c|}
\hline & Frequency & Percentage \\
\hline \multicolumn{3}{|c|}{$\begin{array}{l}\text { A. Attitude towards glaucoma screening } \\
\text { Do you feel you need glaucoma screening? }\end{array}$} \\
\hline Yes & 91 & 80.0 \\
\hline No & 18 & 15.7 \\
\hline No response & 6 & 4.3 \\
\hline \multicolumn{3}{|c|}{ How frequently do you think you need the screening? } \\
\hline Every year & 61 & 53.0 \\
\hline Every 2 years & 24 & 20.9 \\
\hline Every 5 years & 4 & 3.5 \\
\hline Unspecified interval & 2 & 1.7 \\
\hline No response & 24 & 20.9 \\
\hline \multicolumn{3}{|c|}{ B. Screening for glaucoma ever had eye examination? } \\
\hline Yes & 98 & 85.2 \\
\hline No & 17 & 14.8 \\
\hline \multicolumn{3}{|l|}{ Reason for eye examination } \\
\hline Routine & 57 & 49.6 \\
\hline Prompted by symptoms & 19 & 16.5 \\
\hline Unspecified reason & 22 & 19.1 \\
\hline Never had eye examination & 17 & 14.8 \\
\hline \multicolumn{3}{|l|}{ When last were you screened? } \\
\hline$<1$ year ago & 47 & 40.9 \\
\hline 1 - 2 years ago & 23 & 20.0 \\
\hline 2 - 3 years ago & 12 & 10.4 \\
\hline 4 - 5 years ago & 8 & 6.9 \\
\hline$>5$ years ago & 8 & 6.9 \\
\hline Has never been screened & 17 & 14.8 \\
\hline
\end{tabular}

( $<40$ years) having the tendency to take up routine eye examination than those older than or equal to 40 years. This agrees with findings among relatives of glaucoma patients [8] where older relatives appeared to be disinclined to eye screening. A variety of reasons were proffered including relatively stable requirement for spectacles, poorer mobility, and the cost of the eye test itself. Though we did not assess the effect of these variables on glaucoma screening uptake in our study, it seems most unlikely that cost of eye test and mobility would influence uptake of glaucoma screening among ophthalmologists in Nigeria. Simple glaucoma diagnostic resources are readily available and accessible to these eye care providers. However, against the backdrop of poor financial remuneration of eye care personnel in Nigeria, advanced glaucoma screening and evaluation using high technology and expensive equipment such as optical coherence tomography can be cost challenging. Benatar in South Africa noted that an effective National Health Insurance (NHI) will ensure that everyone has access to appropriate, efficient and quality health services [13]. This is corroborated by an Australian survey which observed an enhanced uptake of routine eye screening made possible by a universal insurance coverage [14]. Baba et al. placed the poor performance of Nigeria's NHIS within the wider context of a fragmented approach to healthcare that involves both federal and state governments, a deterioration in the public health services caused by "brain drain" and lack of resources, and the high levels of poverty encountered in Nigeria [15].

Further cross-cadre studies exploring the definite reasons for poor self-eye care is suggested to enhance promotive and preventive eye care among these high cadre eye care professionals.

Known risk factors for primary open angle glaucoma (POAG) may be classified as raised intraocular pressure (IOP) and non-IOP factors. Non-IOP risk factors include old age especially after the age of 40 years, black race, thinner central corneal thickness (CCT), duration of optic disc hemorrhage, myopia, family history of glaucoma, low ocular perfusion pressure, systemic hypertension, cardiovascular disease, cerebrovascular disease, systemic hypotension (for low-tension glaucoma), raised blood cholesterol, atherosclerosis, diabetes mellitus, migraine headaches, ability to taste phenylthiourea [13].

Identification of risk factors is a predictive tool for case finding and also helps in targeted eye health education with regards to glaucoma care [12]. The presence of risk factors in this study population such as positive 
family history of glaucoma, myopia, hypertension, diabetes mellitus, black race and age $>40$ years were notable. Moreover, the whole study population can be described as being at risk of developing glaucoma, being Africans of West African origin.

The conclusion drawn from this study and the generalization of its findings is limited by its conference-based study design as a significant number of ophthalmologists who did not attend the 2013 annual congress of OSN were not captured in the survey. A cross-national survey involving all registered ophthalmologists in Nigeria is therefore suggested.

\section{Conclusion}

In conclusion, there is high positive perception towards glaucoma screening among ophthalmologists in Nigeria. However practice of regular glaucoma screening practice was suboptimal against the backdrop of presumed high level of knowledge of the risk of blindness from glaucoma among this group of professionals. There is no correlation between positive perception/glaucoma screening practice and sex, age group, religion, professional status, positive family history, and presence of myopia. This highlights the need for an in-house promotion campaign by eye health educators aimed at enhancing self-eye care of the eye care providers. In addition, affordable high technology-based glaucoma screening should be made possible through provision of effective health insurance program by government and health care policy makers in Nigeria.

\section{Conflict of Interest}

The authors declare no conflict of interest in this work.

\section{External Source of Funding}

None declared.

\section{References}

[1] Tielsch, J.M., Sommer, A., Katz, J., Royall, R.M., Quigley, H.A. and Javitt, J. (1991) Racial Variations in the Prevalence of Primary Open Angle Glaucoma. The Baltimore Eye Survey. Journal of American Medical Association, 266, 369-374. http://dx.doi.org/10.1001/jama.1991.03470030069026

[2] Quigley, H.A. and Broman, A.T. (2006) The Number of People with Glaucoma Worldwide in 2010 and 2020. British Journal of Ophthalmology, 90, 262-267. http://dx.doi.org/10.1136/bjo.2005.081224

[3] Abdull, M.A., Sivasubramaniam, S., Murthy, G.V.S, Gilbert, C., Ezelum, C. and Rabiu, M.M. (2009) Causes of Blindness and Visual Impairment in Nigeria: The Nigerian National Blindness and Visual Impairment Survey. Investigative Ophthalmology and Visual Science, 50, 4114-4120. http://dx.doi.org/10.1167/iovs.09-3507

[4] Bowman, R.J. (2006) How to Manage Glaucoma in a Patient in Africa. Journal of Community Eye Health, $19,38-39$.

[5] Baker. H., Cousens, S.N. and Murdoch, I.E. (2010) Poor Public Health Knowledge about Glaucoma: Fact or Fiction? Eye, 24, 653-657.

[6] Adegbehingbe, B.O. and Bisiriyu, L.A. (2008) Knowledge, Attitude and Self Care Practices Associated with Glaucoma among Hospital Workers in Ile-Ife, Osun State, Nigeria. Tanzania Journal of Health Research, 10, 240-245.

[7] Altangerel, U., Nallamshetty, H.S., Uhler, T., Fontanarosa, J., Steinmann, W.C., Almodin, J.M., Chen, B.H. and Henderer, J.D. (2009) Knowledge about Glaucoma and Barriers to Follow-Up Care in a Community Glaucoma Screening Programme. Canadian Journal of Ophthalmology, 44, 66-69. http://dx.doi.org/10.3129/i08-175

[8] Eke, T., Reddy, M.A. and Karawastowky, W.S.S. (1999) Glaucoma Awareness and Screening Uptake in Relatives of People with Glaucoma. Eye, 13, 647-649. http://dx.doi.org/10.1038/eye.1999.175

[9] Allen, R.C. (1994) Medical Management of Glaucoma In: Jacobiec, A.D., Ed., Principles and Practice of Ophthalmology: Clinical Practice, Vol. 3, Saunders, Philadelphia, 1569-1573.

[10] Komolafe, O.O., Omolase, C.O., Bekibele, C.O., Ogunleye, O.A., Komolafe, O.A. and Omotayo, F.O. (2013) Awareness and Knowledge of Glaucoma among Workers in a Nigerian Tertiary Health Care Institution. Middle East African Journal of Ophthalmology, 20, 163-167. http://dx.doi.org/10.4103/0974-9233.110609

[11] Livingston, P.M., Lee, S.E., De Paola, C., Carson, C.A., Guest, C.S. and Taylor, H.R. (1995) Knowledge of Glaucoma and Its Relationship to Self-Care Practices in a Population Sample. Australian and New Zealand Journal of Ophthalmology, 23, 37-41. http://dx.doi.org/10.1111/j.1442-9071.1995.tb01643.x 
[12] Omoti, A.E. and Edema, O.T. (2007) A Review of the Risk Factors in Primary Open Angle Glaucoma. Nigerian Journal of Clinical Practice, 10, 79-82.

[13] Benatar, S.R. (2011) National Health Insurance-What the People Want, Need and Deserve. South African Medical Journal, 10, 678.

[14] McCarty, C., Lloyd-Smith, C., Lee, S., Livingston, P., Stanislavsky, Y. and Taylor, H. (1998) Use of Eye Care Services by People with Diabetes: The Melbourne Visual Impairment Project. British Journal of Ophthalmology, 82, 410414. http://dx.doi.org/10.1136/bjo.82.4.410

[15] Baba, M. and Omotara, B. (2015) Nigeria’s Public Health: Gains and Challenges 2012. http://www.equilibri.net/nuovo/articols/nigerias-public-health-gains-and-challenges-o 